\title{
PENGARUH INTELLECTUAL CAPITAL, ISLAMIC SOCIAL REPORTING, KEPEMILIKAN PUBLIK, UKURAN DEWAN PENGAWAS SYARIAH DAN JUMLAH RAPAT DEWAN PENGAWAS SYARIAH TERHADAP SOCIAL PERFORMANCE
}

(Studi Empiris Pada Bank Umum Syariah Terdaftar Pada OJK Tahun 20082019)

\author{
Ailsa Nadiyah Shabrina1, Bima Cinintya Pratama ${ }^{2 *}$, Iwan Fakhruddin ${ }^{3}$, \\ Hardiyanto Wibowo 4 \\ Program Studi Akuntansi S1 Fakultas Ekonomi dan Bisnis, Universitas Muhammadiyah \\ Purwokerto \\ bimacp.ump@gmail.com ${ }^{2 *}$
}

\begin{abstract}
ABSTRAK
Tujuan dari penelitian ini adalah untuk mengetahui pengaruh intellectual capital, islamic social reporting, kepemilikan publik, ukuran dewan pengawas syariah dan jumlah Rapat Dewan Pengawas Syariah terhadap Social Performance. Populasi yang digunakan dalam penelitian ini adalah Bank Umum Syariah yang terdaftar di Otoritas Jasa Keuangan Tahun 2008-2019. Teknik pengampilan sampel yang digunakan yaitu teknik purposive sampling dengan menggunakan pooled unbalance sampel sehingga diperoleh sampel sebanyak 14 perusahaan dengan 114 observasi. Teknik analisis data yang digunakan adalah analisis regresi linear berganda dengan bantuan program SPSS. Hasil penelitian ini menunjukkan bahwa variabel intellectual capital dan ukuran dewan pengawas syariah tidak berpengaruh terhadap social performance, sedangkan variabel islamic social reporting dan jumlah rapat dewan pengawas syariah berpengaruh positif terhadap social performance dan variabel kepemilikan publik berpengaruh negatif terhadap social performance.
\end{abstract}

Kata Kunci: Intellectual Capital, Islamic Social Reporting, Kepemilikan Publik, Jumlah rapat dewan pengawas syariah dan kinerja sosial

ABSTRACT

The purpose of this study was to determine the effect of intellectual capital, Islamic social reporting, public ownership, the size of the Sharia Supervisory Board and the number of Sharia Supervisory Board Meetings on Social Performance. The population used in this study is a Sharia Commercial Bank registered with the Financial Services Authority during 2008-2019. The sampling technique used was purposive sampling technique using pooled unbalance samples to obtain a sample of 12 companies with 114 observations. The data analysis technique used is multiple linear regression analysis with the help of the SPSS program. This study indicates that the variables of intellectual capital, public ownership and the size of the sharia supervisory board do not affect social performance. In contrast, the Islamic social reporting variables and the number of sharia supervisory board meetings positively affect social performance.

Keyword: Intellectual Capital, Islamic Social Reporting, Public Ownership, The Size Of The Sharia Supervisory Board, The Number Of Sharia Supervisory Board Meetings And Social Performance 


\section{PENDAHULUAN}

Pengukuran kinerja perbankan syariah berbeda dengan bank konvensional, kinerja bank syariah tidak hanya mengungkapkan tentang nilai-nilai materialistiknya, namun perlu mengungkapkan nilai-nilai spritual dan sosial (Makrufulis, 2019). Pengukuran kinerja perusahaan diperlukan untuk mengetahui apakah kinerja perusahaan dapat dikatakan baik atau buruk (Retnaningsih, Hariyanti, dan Astuti, 2019). Terutama perbankan syariah yang harus mematuhi prinsip islam dan keadilan sosial (Nurgraheni, 2018). Pengukuran kinerja perbankan syariah diantaranya yaitu kontribusi terhadap pembangunan ekonomi, masyarakat dan lingkungan sosial, kepada pemangku kepentingannya, dan pendidikan sumber daya manusia (Hameed dkk., 2004). Pengukuran ini dapat menunjukkan kinerja bank umum syariah yang sesuai dengan prinsip-prinsip syariah (Andraeny dan Putri, 2017).

Intellectual capital dapat digunakan untuk meningkatkan keunggulan kompetitif dalam sebuah perusahaan untuk bersaing. Terutama perusahaan perbankan yang memiliki berbagai risiko terutama risiko kredit. Menurut penelitian Innayah (2020) mengemukakan bahwa keberhasilan dalam perkreditan sangat tergantung pada keterampilan, pengetahuan, pemikiran imajinatif dan pengalaman profesional karyawan bank untuk mengidentifikasi dan menganalisis secara tepat kemungkinan ancaman pada tahap awal pada saat keputusan kredit dibuat dan untuk memecahkan masalah selama persetujuan masa pinjaman kredit.

Berdasarkan penelitian terdahulu mengenai intellectual capital yang dilakukan oleh Chairunissa dan Dewi (2015), Pratama (2016), Pratama (2018), dan Pratama, Wibowo, dan Innayah (2019) menunjukkan hasil bahwa intellectual capital berpengaruh positif terhadap kinerja perusahaan. Pratama (2016) mengemukakan bahwa penggunaan modal intellectual capital yang efisien dan efektif dapat meningkatkan kinerja suatu perusahaan.

Konsep pertanggungjawaban sosial menurut Wibisono (2007) menjelaskan bahwa untuk berperilaku etis dan memenuhi aspek ekonomi, sosial dan lingkungan untuk pembangunan berkelanjutan yang baik sebagai bentuk pertanggungjawaban perusahaan kepada pemangku kepentingan. Konsep pertanggungjawaban sosial dalam islam dikembangkan sesuai dengan prinsip syariah yang dikenal dengan nama islamic social reporting (ISR) (Merina dan Verawaty, 2016).

Penelitian mengenai pertanggungjawaban sosial sudah dilakukan oleh peneliti terdahulu diantaranya Saleh, Zulkifli, dan Muhammad (2011) menemukan bahwa pertanggungjawaban sosial berpengaruh positif terhadap kinerja perusahaan, perusahaan yang berinvestasi lebih di bidang tanggung jawab sosial akan meningkatkan kinerja dan menciptakan loyalitas pada masyarakat dalam jangka panjang. Hasil ini didukung oleh peneliti terdahulu diantaranya Nugroho dan Rahardjo (2014), Evans dan Kartikanindyah (2017), Retnaningsih, Hariyanti dan Astuti (2019) menemukan bahwa pertanggungjawaban sosial berpengaruh positif terhadap kinerja perusahaan.

Menurut Hamdani, Yuliandari, dan Budiono (2017), kepemilikan publik adalah proporsi saham yang dimiliki publik/masyarakat terhadap saham perusahaan yaitu pihak individu atau institusi yang memiliki saham dibawah 5\%. Menurut teori agency, dengan adanya kepemilikan dan kontrol yang dipisahkan menciptakan masalah agensi dalam perusahaan. Rahmawati dan Handayani 
(2017) menyatakan bahwa semakin tinggi kepemilikan suatu perusahaan maka akan semakin baik kinerja perusahaan.

Penelitian kepemilikan publik sudah dilakukan oleh beberapa peneliti terdahulu diantaranya Eforis (2017) dan Irwansyah (2019) menemukan bahwa kepemilikan publik berpengaruh positif terhadap kinerja perusahaan, semakin besar komposisi kepemilikan publik akan memiliki kendali pada suatu perusahaan. Pernyataan tersebut didukung oleh penelitian Haryanti dan Rahardjo (2013) menemukan bahwa kepemilikan publik berpengaruh positif terhadap kinerja perusahaan. Kepemilikan publik digunakan sebagai kontrol terhadap manajer. Semakin tinggi kepemilikan publik maka tekanan untuk mengawasi manajer semakin kuat, sehingga manajer berupaya untuk memenuhi keinginan publik yang akan berdampak pada peningkatan kinerja perusahaan (Raharja, 2013).

Dewan Pengawas Syariah adalah dewan yang bertugas memberikan nasihat dan saran kepada direksi serata mengawasi kegiatan bank agar sesuai dengan prinsip syariah (Nurhayati, Yuliafitri, dan Amrania, 2017). Jumlah anggota dewan pengawas syariah paling kurang 2 (dua) orang atau paling banyak 50\% (lima puluh persen) dari jumlah anggota direksi (Peraturan Bank Indonesia, 2009). Menurut Muttakin dan Ullah (2012), semakin banyak anggota dewan pengawas syariah maka akan mendorong kinerja yang lebih baik pada bidang pengawasan sehingga tingkat kepatuhan syariah menjadi lebih baik serta menurunkan agency problem dan dapat meningkatkan kinerja perusahaan.

Penelitian tentang pengaruh ukuran dewan pengawas syariah sudah dilakukan oleh peneliti terdahulu diantaranya Almutairi dan Quttainah (2017), Nomran, Haron, dan Hasan (2018), dan Nurgraheni (2018) menemukan bahwa ukuran dewan pengawas syariah berpengaruh positif terhadap kinerja perusahaan. Menurut Nurgraheni (2018), jumlah anggota dewan pengawas syariah yang lebih banyak akan lebih intens dalam melakukan pemantauan kegiatan untuk memastikan kegiatan bank sesuai dengan prinsip syariah.

Rapat dewan pengawas syariah adalah rapat yang dilakukan dewan pengawas syariah untuk mengoordinasi dan membahas hal-hal yang terkait kegiatan perbankan syariah agar tetap sesuai dengan prinsip syariah (Peraturan Bank Indonesia, 2009). Keefektifan dewan pengawas syariah akan terlihat apabila sering melakukan pembahasan-pembahasan/diskusi atas masalah yang dikhwatirkan akan melanggar prinsip-prinsip syariah dalam menjalankan operasi bisnis syariah (Purwanti, 2016).

Penelitian tentang pengaruh jumlah rapat dewan pengawas syariah yang telah dilakukan oleh peneliti terdahulu diantaranya Nurmalia dan Ardana (2019), Amalia, Sasongko, dan Bawono (2019), dan Umam dan Ginanjar (2020) menemukan bahwa jumlah rapat dewan pengawas syariah berpengaruh terhadap kinerja perusahaan. Amalia dkk. (2019) mengemukakan bahwa semakin sering dewan pengawas syariah melakukan rapat, maka fungsi pengawasan semakin efisien dan efektif dalam mengawasi kinerja manajemen sehingga dapat meningkatkan kinerja perusahaan.

Berdasarkan uraian latar belakang masalah tersebut, maka penelitian ini dilakukan untuk mengetahui atau melihat seberapa pengaruhnya IC, ISR, Kepemilikan Publik, Ukuran DPS, dan Jumlah Rapat DPS terhadap Social 
Performance. Studi kasus pada Bank Umum Syariah yang terdaftar di OJK tahun 2008-2019.

\section{TINJAUAN PUSTAKA}

\section{Resource-Based Theory (RBT)}

Resource-Based Theory (RBT) adalah teori yang digunakan untuk memberikan gambaran sebuah keunggulan bagi perusahaan, keunggulan perusahaan akan tercipta apabila sebuah perusahaan mempunyai sumber daya profesional yang tidak dimiliki oleh perusahaan lain (Wernerfelt, 1984). RBT berfungsi sebagai kerangka kerja penting yang digunakan sebagai dasar untuk memprediksi dan menjelaskan keunggulan kompetitif dan kinerja perusahaan (Barney dkk., 2011). Menurut Kozlenkova, et al. (2014) ada 4 karakteristik untuk menilai bagaimana potensi sumber daya akan menciptakan keunggulan kompetitif yang berkelanjutan yang disingkat dengan VRIO yang terdiri atas valuable, rare, imitable, dan organization.

\section{Stakeholder Theory}

Menurut Freeman (1984) stakeholder merupakan kelompok maupun individu yang mempengaruhi atau dipengaruhi oleh proses pencapaian tujuan suatu organisasi, sehingga perubahaan dapat terjadi pada eksternal dan internal. Bentuk perhatian perusahaan terhadap stakeholder yaitu dengan melakukan pengungkapan informasi sosial dan kinerja sosial perusahaan(Bayoud dkk., 2012). Informasi dan kinerja sosial diungkapkan dalam sebuah laporan pertanggungjawaban sosial atau islamic social reporting dalam perbankan syariah (Ullman, 1985). Berdasarkan teori stakeholder tanggung jawab sosial dilakukan di berbagai aspek seperti pegawai, masyarakat, lingkungan, dan ekonomi (Prasetyo dan Meiranto, 2017).

\section{Agency Theory}

Teori ini menjelaskan hubungan antara pemilik dan pemegang saham (principal) dan manajemen (agent). Dalam hal ini hubungan keagenan merupakan sebuah kontrak antara satu orang atau lebih (principal) yang mempekerjakan orang lain (agent) untuk memberikan suatu jasa dan kemudian mendelegasikan wewenang pengambilan keputusan kepada agen tersebut (Jensen dan Meckling, 1976). Haryanti dan Rahardjo (2013) menjelaskan bahwa kepemilikan publik menjadi kontrol terhadap manajer. Semakin tinggi kepemilikan publik maka tekanan untuk mengawasi manajer semakin kuat, sehingga manajer berupaya untuk memenuhi keinginan publik yang akan berdampak pada peningkatan kinerja perusahaan (Raharja, 2013).

Selain itu, penerapan dewan pengawas syariah pada perusahaan diharapkan dapat mengurangi timbulnya agency cost. Semakin banyak dewan pengawas syariah maka pengawasan juga lebih baik sehingga tingkat kepatuhan syariah menjadi lebih baik dan dapat menurunkan masalah agensi yang dilakukan oleh pihak manajemen bank syariah sehingga kinerja perusahaan menjadi lebih baik (Muttakin dan Ullah, 2012). 


\section{Pengaruh Intellectual Capital terhadap Social Performance}

Resource-Based Theory (RBT) adalah teori yang digunakan untuk memberikan gambaran sebuah keunggulan bagi perusahaan, keunggulan perusahaan akan tercipta apabila sebuah perusahaan mempunyai sumber daya profesional yang tidak dimiliki oleh perusahaan lain (Wernerfelt, 1984). Intellectual capital merupakan sumber daya yang berfungsi inti dalam penciptaan nilai dan keunggulan kompetitif dari perusahaan (Pratama, 2016).

Penelitian yang dilakukan oleh Chairunissa dan dewi (2015) Pratama (2016), Pratama (2018), dan Pratama (2019) menemukan bahwa intellectual capital berpengaruh positif terhadap kinerja perusahaan. Pratama (2016) menjelaskan bahwa suatu perusahaan yang dapat menggunakan IC secara lebih efisien, maka dapat meningkatkan kinerja perusahaan tersebut. Berdasarkan uraian tersebut, maka diajukan hipotesis sebagai berikut :

\section{$\mathrm{H}_{1}$ : Intellectual Capital berpengaruh positif terhadap social performance.}

\section{Pengaruh Islamic Social Repoting terhadap Social Performance}

Konsep pertanggungjawaban sosial menurut Wibisono (2007) menjelaskan bahwa untuk berperilaku etis dan memenuhi aspek ekonomi, sosial dan lingkungan untuk pembangunan berkelanjutan yang baik sebagai bentuk pertanggungjawaban perusahaan kepada pemangku kepentingan. Pengungkapan pertanggungjawaban sosial tidak hanya dilakukan oleh perbankan konvensional tetapi juga oleh perbankan syariah (Retnaningsih, Hariyanti dan Astuti, 2019).

Penelitian terdahulu yang dilakukan oleh Saleh (2011), Nugroho dan Rahardjo (2014), Evans dan Kartikanindyah (2017) dan Retnaningsih, Hariyanti dan Astuti (2019) menemukan bahwa pertanggungjawaban sosial berpengaruh positif terhadap kinerja perusahaan. Malik dan Nadeem (2014) menyimpulkan bahwa lembaga keuangan yang menerapkan tanggung jawab sosial lebih banyak dalam operasi mereka, maka akan memiliki kinerja perusahaan yang lebih baik dibandingkan perusahaan yang lebih sedikit menerapkannya. Berdasarkan uraian tersebut, maka diajukan hipotesis sebagai berikut :

$\mathrm{H}_{2}$ : Islamic Social Reporting berpengaruh positif terhadap social performance.

\section{Pengaruh Kepemilikan Publik terhadap Social Performance}

Menurut Hamdani, Yuliandari, dan Budiono (2017), kepemilikan publik adalah proporsi saham yang dimiliki publik/masyarakat terhadap saham perusahaan yaitu pihak individu atau institusi yang memiliki saham dibawah 5\%. Berdasarkan teori agency, dengan adanya kepemilikan dan kontrol yang dipisahkan menciptakan masalah agensi dalam perusahaan. Upaya untuk mengurangi masalah agency problem dan agency cost adalah dengan meningkatkan struktur kepemilikan (Jensen dan Meckling, 1976).

Berdasarkan penelitian terdahulu yang dilakukan oleh Haryanti dan Rahardjo (2013), Eforis (2017), dan Irwansyah (2019) menemukan bahwa kepemilikan publik berpengaruh positif terhadap kinerja perusahaan. Wardani (2012) menyatakan bahwa semakin banyak kepemilikan saham oleh publik, dan semakin meningkatkan pengungkapan laporan keuangan akan semakin 
meningkatkan kepercayaan publik terhadap perusahaan. Berdasarkan uraian tersebut, maka diajukan hipotesis sebagai berikut :

H3 : Kepemilikan Publik berpengaruh positif terhadap social performance.

\section{Pengaruh Ukuran Dewan Pengawas Syariah terhadap Social Performance}

Dewan Pengawas Syariah adalah dewan yang bertugas memberikan nasihat dan saran kepada direksi serta mengawasi kegiatan bank agar sesuai dengan prinsip syariah (Nurhayati, Yuliafitri, dan Amrania, 2017). Jumlah anggota DPS paling kurang 2 (dua) orang atau paling banyak 50\% (lima puluh persen) dari jumlah anggota direksi (Peraturan Bank Indonesia).

Penelitian terdahulu yang dilakukan oleh Almutairi dan Quttainah (2017), Nomran dkk. (2018), dan Nurgraheni (2018) menemukan bahwa ukuran dewan pengawas syariah berpengaruh positif terhadap kinerja perusahaan. Muttakin dan Ullah (2012) mengatakan bahwa semakin banyak anggota DPS maka akan mendorong kinerja perusahaan yang lebih baik pada bidang pengawasan sehingga tingkat kepatuhan syariah menjadi lebih baik serta menurunkan agency problem sehingga dapat meningkatkan kinerja perusahaan. Berdasarkan uraian tersebut, maka diajukan hipotesis sebagai berikut :

$\mathrm{H}_{4}$ : Ukuran Dewan Pengawas Syariah berpengaruh positif terhadap social performance.

\section{Pengaruh Jumlah Rapat Dewan Pengawas Syariah terhadap Social Performance}

Rapat dewan pengawas syariah adalah rapat yang dilakukan dewan pengawas syariah untuk mengoordinasi dan membahas hal-hal yang terkait kegiatan perbankan syariah agar tetap sesuai dengan prinsip syariah (Peraturan Bank Indonesia, 2009). Keefektifan dewan pengawas syariah akan terlihat apabila sering melakukan pembahasan-pembahasan/diskusi atas masalah yang dikhwatirkan akan melanggar prinsip-prinsip syariah dalam menjalankan operasi bisnis syariah (Purwanti, 2016).

Penelitian terdahulu yang dilakukan oleh Nurmalia dan Ardana (2019), Amalia dkk. (2019), dan Umam dan Ginanjar (2020) menemukan bahwa jumlah rapat berpengaruh terhadap kinerja perusahaan. mengawasi kinerja manajemen sehingga dapat meningkatkan kinerja perusahaan. Amalia dkk. (2019) mengemukakan bahwa semakin sering dewan pengawas syariah melakukan rapat, maka fungsi pengawasan semakin efisien dan efektif dalam mengawasi kinerja manajemen sehingga dapat meningkatkan kinerja perusahaan. Berdasarkan uraian tersebut, maka diajukan hipotesis sebagai berikut :

H5 : Jumlah Rapat Dewan Pengawas Syariah berpengaruh positif terhadap social performance.

\section{METODE PENELITIAN}

\section{Populasi dan Sampel}

Populasi dan sampel yang digunakan dalam penelitian ini adalah Bank Umum Syariah tahun 2008-2019. Teknik pengambilan sampel yang digunakan dalam penelitian ini adalah purposive sampling dengan menggunakan pooled 
unbalance sampel. Berdasarkan kriteria sampel yang telah dipilih dalam penelitian ini, maka diperoleh sampel penelitian sebanyak 12 perusahaan untuk setiap tahunnya dimana periode yang digunakan dalam penelitian adalah tahun 2008-2019. Sehingga total keseluruhan sampel yang digunakan adalah sebanyak 114.

Tabel 1. Tabel Penentuan Jumlah Sampel

\begin{tabular}{llll}
\hline No & Kriteria & Jumlah \\
\hline $\mathbf{1}$ & Total Bank Umum Syariah Tahun 2008-2019 & 136 \\
\hline $\mathbf{2}$ & $\begin{array}{l}\text { Bank Victoria syariah Tahun 2011 dan 2012 tidak } \\
\text { ditemukan laporan keuangan }\end{array}$ & $(2)$ \\
\hline $\mathbf{3}$ & $\begin{array}{l}\text { Bank Aceh Syariah dan BPD NTBS Tahun 2012-2019 dan } \\
\text { BTPNS Tahun 2014-2017 tidak memiliki kelengkapan } \\
\text { variabel kepemilikan publik }\end{array}$ & \\
\hline Total Jumlah Sampel Selama Periode Penelitian & $\mathbf{1 1 4}$ \\
\hline
\end{tabular}

\section{DEFINISI OPERASIONAL DAN PENGUKURAN VARIABEL} Social Performance

Social performance adalah pengukuran kinerja bank syariah lebih menggambarkan nilai Islam pada praktiknya (Violita, 2018). Variabel social performance yang digunakan dalam penelitian ini mengacu pada penelitian Nurgraheni (2018) yaitu kinerja sosial bank syariah. Ada empat tema yaitu kontribusi terhadap pembangunan ekonomi, kepada masyarakat dan lingkungan, kepada pemangku kepentingan, dan pendidikan sumber daya manusia.

a. Kontribusi pembangunan ekonomi yang diwakili oleh rasio modal bagi hasil pembiayaan dan intensitas peran keagenan perbankan syariah.

$\begin{gathered}\text { Rasio Model bagi hasil } \\ \text { Pembiayaan terhadap Total Pembiayaan MMR }\end{gathered}=\frac{\text { Mudharabah + Musyarakah }}{\text { Total Pembiayaan }}$

Kriteria penghitungan AKI adalah sebagai berikut : Skor $5=\mathrm{AKI}>50 \%$; Skor $4=40 \%<$ MMR $\leq 50 \%$; Skor $3=30 \%<$ MMR $\leq 40 \%$; Skor $2=20 \%<$ MMR $\leq 30 \%$; dan Skor $1=$ MMR $\leq 20 \%$.

$$
\text { Intensitas Perbankan Islam (IAR) }=\frac{\text { Deposito Mudharabah (URIA) }}{\text { Total Pendanaan }}
$$

Kriteria penghitungan AR adalah sebagai berikut : Skor $5=$ IAR $>90 \%$; Skor $4=80 \%<$ IAR $\leq 90 \%$; Skor $3=70 \%<$ IAR $\leq 80 \%$; Skor $2=60 \%<$ IAR $\leq 70 \%$; dan Skor $1=$ IAR $\leq 20 \%$.

b. Kontribusi Kepada Masyarakat diwakili oleh rasio qardh pembiayaan dan zakat kinerja.

$$
\text { Rasio Pembiayaan Qardh }(\mathrm{QR})=\frac{\text { Pembiayaan Qardh }}{\text { Total Pembiayaan }}
$$


Kriteria penghitungan QR ratio adalah sebagai berikut : Skor $5=\mathrm{QR}>$ $5 \%$; Skor $4=3 \%<\mathrm{QR} \leq 5 \%$; Skor $3=2 \%<\mathrm{QR} \leq 3 \%$; Skor $2=1 \%<\mathrm{QR} \leq$ $2 \%$; dan Skor $1=\mathrm{QR} \leq 1 \%$.

$$
\text { Rasio Kinerja Zakat }(\mathrm{ZR})=\frac{\text { Distribusi Zakat }}{\text { Laba Sebelum Pajak }}
$$

Kriteria penghitungan rasio ZR adalah sebagai berikut: Skor $5=\mathrm{ZR}>$ $2,5 \%$; Skor $4=2 \%<Z R \leq 2,5 \%$; Skor $3=1,5 \%<Z R \leq 2 \%$; Skor $2=1 \%<$ $\mathrm{ZR} \leq 1,5 \%$; dan Skor $1=\mathrm{ZR} \leq 1 \%$.

c. Kontribusi kepada stakeholder diwakili oleh rasio kontribusi terhadap Mudharib dan kontribusi untuk Mudharab Mutlaqah Pemegang Rekening Investasi.

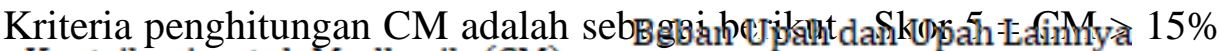

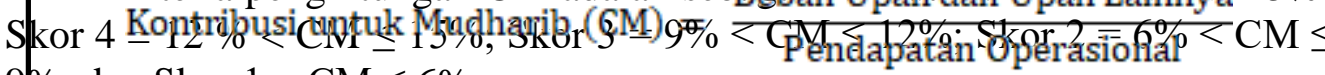
$9 \%$; dan Skor $1=\mathrm{CM} \leq 6 \%$.

$$
\text { Kontribusi URIA }(\mathrm{CUH})=\frac{\text { Distribusi Bagi Hasil }}{\text { Total Investasi Mudharabah Mutlaqah }}
$$

Kriteria penghitungan $\mathrm{CUH}$ adalah sebagai berikut : Skor $5=\mathrm{CUH}>$ $15 \%$; Skor $4=12 \%<\mathrm{CUH} \leq 15 \%$; Skor $3=9 \%<\mathrm{CUH} \leq 12 \%$; Skor $2=6 \%$ $<\mathrm{CUH} \leq 9 \%$; dan Skor $1=\mathrm{CUH} \leq 6 \%$.

d. Kontribusi peningkatan kapasitas SDM diwakili oleh rasio kontribusi terhadap pengembangan SDM.

$$
\text { Kontribusi SDM }(\text { CHRD })=\frac{\text { Biaya Pendidikan dan Pelatihan }}{\text { Keuntungan Setelah Pajak }}
$$

Kriteria penghitungan CHRD adalah sebagai berikut : Skor $5=\mathrm{CHRD}>$ $15 \%$; Skor $4=12 \%<$ CHRD $\leq 15 \%$; Skor $3=9 \%<$ CHRD $\leq 12 \%$; Skor $2=$ $6 \%<\mathrm{CHRD} \leq 9 \%$; dan Skor $1=\mathrm{CHRD} \leq 6 \%$.

Rumus Kinerja Sosial (SP) adalah :

$$
\mathrm{SP}=\frac{\text { Total Score }}{35} \times 100 \%
$$

\section{Intellectual Capital (IC)}

Barney (1991) mendefinisikan bahwa intellectual capital adalah sumber daya yang berfungsi sebagai inti penciptaan nilai dan keunggulan bagi perusahaan untuk bersaing. Variabel Intellectual Capital yang digunakan dalam penelitian ini mengacu pada penelitian Ulum (2013) : 


\section{$i B-V A I C=i B-V A C A+i B-V A H U+i B-S T V A$}

Dimana:

iB-VAIC = Nilai tambah koefisien intelektual

iB-VACA $=$ VA / CE; koefisien efisiensi modal digunakan

iB-VAHU = VA $/ \mathrm{HC}$; koefisien efisiensi modal manusia

iB-STVA $=$ SC / VA; koefisien efisiensi modal struktural

VA $\quad=$ OUT - IN atau VA juga dapat dihitung dengan Formulasi: OP + $\mathrm{EC}+\mathrm{D}+\mathrm{A}$; VA adalah perhitungan output (OUT) yang dihitung dari total pendapatan dikurangi dengan input (IN) yang dihitung dari beban usaha atau operasional dan beban non operasional, kecuali beban kepegawaian/karyawan; laba operasi/laba usaha (OP); beban karyawan (EC); depresiasi (D); dan amortisasi (A).

$\mathrm{HC}=$ beban karyawan

$\mathrm{SC} \quad=\mathrm{iB}-\mathrm{VA}-\mathrm{HC}$; modal struktural

$\mathrm{CE} \quad=$ dana yang tersedia (total ekuitas).

\section{Islamic Social Reporting}

Retnaningsih, Hariyanti dan Astuti (2019) menjelaskan bahwa pengungkapan tanggung jawab sosial tidak hanya dilakukan oleh perbankan konvensional tetapi juga oleh perbankan syariah. Konsep pertanggungjawaban sosial dalam islam dikembangkan sesuai dengan prinsip syariah yang dikenal dengan nama islamic social reporting (ISR) (Merina dan Verawaty, 2016). Perhitungan islamic social reporting menggunakan indeks standar pelaporan pertanggungjawaban sosial yang ditetapkan oleh AAOIFI (Accounting and Auditing Organization for Islamic Financial Institutions) (Nurhayati, Yuliafitri dan Amrania, 2017). Variabel islamic social reporting yang digunakan dalam penelitian ini mengacu pada penelitian Merina dan Verawaty (2016). Pada penelitian ini islamic social reporting diukur dengan menggunakan indeks yaitu 43 item indeks pengungkapan yang dikategorikan menjadi enam, yaitu keuangan investasi, produk dan atau jasa, karyawan, lingkungan, dan tata kelola perusahaan. Rumus perhitungan ISR adalah sebagai berikut :

$$
\operatorname{ISR}_{\mathrm{j}}=\frac{\sum \mathrm{X}_{\mathrm{ij}}}{\mathrm{n}_{\mathrm{j}}}
$$

Dimana :

$I S R_{j} \quad=$ Islamic Social Reporting Index perusahaan $\mathrm{j}$

$\mathrm{N}_{\mathrm{j}} \quad=$ jumlah item untuk perusahaan $\mathrm{j}, \mathrm{nj}=43$

$\mathrm{X}_{\mathrm{ij}} \quad=1$, jika item $\mathrm{i}$ diungkapkan, $0=$ jika item i tidak diungkapkan.

\section{Kepemilikan Publik}

Kepemilikan publik adalah kepemilikan saham yang dimiliki oleh publik, kepemilikan bisa oleh sebuah group atau individu (Arifulsyah, 2016). Variabel kepemilikan publik digunakan dalam penelitian ini mengacu pada penelitian Eforis (2017) Rumus perhitungan sebagai berikut : 
RATIO: Reviu Akuntansi Kontemporer Indonesia 2021, 2 (2)

$$
K P=\frac{\sum \text { saham yang dimiliki Publik }}{\sum \text { Saham yang beredar }} \times 100 \%
$$

\section{Ukuran Dewan Pengawas Syariah}

Dewan Pengawas Syariah adalah dewan yang bertugas memberikan nasihat dan saran kepada direksi serata mengawasi kegiatan bank agar sesuai dengan prinsip syariah (Nurhayati, Yuliafitri, dan Amrania, 2017). Jumlah anggota dewan pengawas syariah paling kurang 2 (dua) orang atau paling banyak 50\% (lima puluh persen) dari jumlah anggota direksi (Peraturan Bank Indonesia, 2009). Variabel ukuran dewan pengawas syariah digunakan dalam penelitian ini mengacu pada penelitian Nurgraheni (2018). Rumus perhitungan sebagai berikut :

Ukuran DPS $=\sum$ Anggota DPS

\section{Jumlah Rapat Dewan Pengawas Syariah}

Rapat dewan pengawas syariah adalah rapat yang dilakukan dewan pengawas syariah untuk mengoordinasi dan membahas hal-hal yang terkait kegiatan perbankan syariah agar tetap sesuai dengan prinsip syariah (Peraturan Bank Indonesia, 2009). Variabel jumlah rapat dewan pengawas digunakan dalam penelitian ini mengacu pada penelitian Nurgraheni (2018). Rumus perhitungan sebagai berikut :

Jumlah Rapat DPS $=\sum$ Rapat DPS selama 1 tahun

\section{Analisis Data}

Teknik analisis data yang digunakan pada penelitian ini adalah analisis regresi berganda. Metode analisis regresi berganda digunakan untuk melihat pengaruh variabel independen terhadap variabel dependennya (Ghozali, 2013). Model regresi linear berganda yang digunakan untuk menguji hipotesis dalam penelitian ini adalah sebagai berikut:

$$
S P_{i t}=\alpha+\beta_{1} I C+\beta_{2} I S R+\beta_{3} K P+\beta_{4} U D P S+\beta_{5} J R D P S+\varepsilon
$$

\section{Keterangan:}

SP : Kinerja Sosial bank syariah

$\alpha \quad$ : Konstanta

$\beta_{1}-\beta_{5}$ : Koefisien regresi dari setiap variabel independen

IC : Intellectual Capital

ISR : Islamic Social Reporting

KP : Kepemilikan Publik

UDPS : Ukuran Dewan Pengawas Syariah

JRDPS: Jumlah Rapat Dewan Pengawas Syariah

$\varepsilon \quad:$ Error term 


\section{Hasil dan Pembahasan Analisis Statistik Deskriptif}

Tabel 2. Hasil Uji Statitistik Deskriptif

\begin{tabular}{|c|c|c|c|c|c|}
\hline & $\mathrm{N}$ & Minimum & Maximum & Mean & $\begin{array}{l}\text { Std. } \\
\text { Deviation }\end{array}$ \\
\hline SP & 114 & 0.1429 & 0.7714 & 0.512030 & 0.1333713 \\
\hline IC & 114 & -10.0522 & 69.1047 & 3.096992 & 6.6458421 \\
\hline ISR & 114 & 0.1628 & 0.6744 & 0.429213 & 0.1133038 \\
\hline $\mathrm{KP}$ & 114 & 0.000000001 & 0.3032 & 0.048175 & 0.0817747 \\
\hline UDPS & 114 & 2 & 4 & 2.42 & 0.513 \\
\hline JRDPS & 114 & 4 & 30 & 14.21 & 4.248 \\
\hline $\begin{array}{l}\text { Valid } \mathrm{N} \\
\text { (listwise) }\end{array}$ & 114 & & & & \\
\hline
\end{tabular}

Sumber : Data SPSS 20 diolah tahun 2020.

Berdasarkan tabel 2 diatas, menunjukkan bahwa pengujian terhadap 114 sampel amatan menunjukan bahwa social performance memiliki nilai rata-rata (mean) sebesar 0,512030 yang mengindikasikan bahwa kinerja bank umum syariah cukup baik karena diatas 50\%. Sedangkan, Intellectual Capital memiliki nilai rata-rata (mean) sebesar 3,096992. Kemudian, islamic social reporting memiliki nilai rata-rata (mean) sebesar 0,429213 atau 42,92\%. Selanjutnya, kepemilikan publik memiliki nilai rata-rata (mean) sebesar 0,048175 atau 4,81\%. Lalu, ukuran dewan pengawas syariah memiliki nilai rata-rata (mean) sebesar 2,42 . Dan jumlah rapat dewan pengawas syariah memiliki nilai rata-rata (mean) sebesar 14,21.

\section{Analisis Regresi Linier Berganda}

Tabel 3. Hasil Uji Analisis Regresi Linier Berganda Coefficients $^{\mathrm{a}}$

\begin{tabular}{|c|c|c|c|c|c|c|}
\hline \multicolumn{2}{|c|}{ Model } & \multicolumn{2}{|c|}{$\begin{array}{l}\text { Unstandardized } \\
\text { Coefficients }\end{array}$} & \multirow{2}{*}{$\begin{array}{l}\text { Standardized } \\
\text { Coefficients } \\
\text { Beta }\end{array}$} & \multirow[t]{2}{*}{$\bar{T}$} & \multirow[t]{2}{*}{ Sig. } \\
\hline & & B & $\begin{array}{l}\text { Std. } \\
\text { Error }\end{array}$ & & & \\
\hline \multirow[t]{6}{*}{1} & (Constant) & 0.240 & 0.091 & & 2.624 & 0.010 \\
\hline & IC & 0.001 & 0.002 & 0.072 & 0.801 & 0.425 \\
\hline & ISR & 0.319 & 0.107 & 0.271 & 2.987 & 0.003 \\
\hline & $\mathrm{KP}$ & -0.175 & 0.153 & -0.107 & -1.145 & 0.255 \\
\hline & UDPS & 0.014 & 0.024 & 0.053 & 0.580 & 0.563 \\
\hline & JRDPS & 0.007 & 0.003 & 0.236 & 2.508 & 0.014 \\
\hline
\end{tabular}

a. Dependent Variable : Social Performance

Sumber : Data SPSS 20 diolah tahun 2020.

Berdasarkan pada hasil koefisien regresi di atas, maka dapat dibuat model persamaan regresi linier berganda sebagai berikut :

$$
S P=0,240+0,001 I C+0,319 I S R-0,175 K P+0,014 \text { UDPS }+0,007 J R D P S+\varepsilon
$$




\section{Hasil Uji Determinan (Adjusted $\mathbf{R}^{2}$ )}

Berdasarkan hasil uji koefisien determinasi dapat dianalisi bahwa pengujian menunjukkan hasil nilai Adjusted $R$ Square sebesar 0,105 atau seebsar 10,5\%. Hasil ini diartikan bahwa variabel dependen yaitu social performance dapat dijelaskan oleh variabel intellectual capital, islamic social reporting, kepemilikan publik, ukuran dewan pengawas syariah, dan jumlah rapat dewan pengawas syariah seebsar $10,5 \%$, sedangkan sisanya sebesar $89,5 \%$ dijelaskan oleh variabel diluar model regresi, seperti reputasi dewan pengawas syariah (Nugraheni, 2018), rangkap jabatan dewan pengawas syariah (Nomran, 2018), keputusan pendanaan (Amalia, 2019), ukuran dewan direksi dan ukuran komite audit (Nugroho, 2014).

\section{Tabel 4. Hasil Koefisien Determinasi $\left(\mathbf{R}^{2}\right)$}

\section{Model Summary}

\begin{tabular}{llll}
\hline Model & R & R Square & Adjusted R Square \\
\hline 1 & $0.380^{\mathrm{a}}$ & 0.144 & 0.105 \\
\hline \multicolumn{4}{r}{ a.Predictors : (Constant), IC, ISR,KP, UDPS, JRDPS } \\
Sumber : Data SPSS 20 diolah tahun 2020.
\end{tabular}

\section{Hasil Uji Statistik F}

Tabel 5. Hasil Uji Model (Uji Statistik F)

\begin{tabular}{lllllll}
\hline Model & & $\begin{array}{l}\text { Sum of } \\
\text { Squares }\end{array}$ & Df & $\begin{array}{l}\text { Mean } \\
\text { Square }\end{array}$ & F & Sig. \\
\hline 1 & Regression & 0.290 & 5 & 0.058 & 3.642 & $0.004^{\mathrm{b}}$ \\
& Residual & 1.720 & 108 & 0.016 & & \\
& Total & 2.010 & 113 & & & \\
\hline
\end{tabular}

a. Dependent Variable: SP

b. Predictors: (Constant), Jumlah Rapat DPS, ISR, IC, UDPS, KP

Sumber : Data SPSS 20 diolah tahun 2020.

Berdasarkan tabel 5 menunjukkan besarnya nilai $\mathrm{F}$ hitung adalah 3,642 dinyatakan dengan tanda positif maka arah hubungannya adalah positif. Nilai secara statistik meenunjukkan hasil yang signifikan pada $\alpha=0,05$ yaitu sebesar 0,004 artinya nilai signifikansi $<0,05$. Hal ini menunjukkan bahwa model tersebut layak digunakan untuk memprediksi pengaruh Intellectual Capital, Islamic Social Reporting, Kepemilikan Publik, Ukuran dewan Pengawas Syariah, dan Jumlah Rapat Dewan Pengawas Syariah yang diproksikan dengan Social Performance.

\section{Hasil Uji t}

Tabel 6. Hasil Uji Signifikansi Parameter Individual (Uji Statistik t)

\begin{tabular}{|c|c|c|c|c|c|}
\hline \multirow[t]{2}{*}{ Model } & \multicolumn{2}{|c|}{$\begin{array}{l}\text { Unstandardized } \\
\text { Coefficients }\end{array}$} & $\begin{array}{l}\text { Standardized } \\
\text { Coefficients }\end{array}$ & $\bar{T}$ & Sig. \\
\hline & $\mathrm{B}$ & $\begin{array}{l}\text { Std. } \\
\text { Error }\end{array}$ & Beta & & \\
\hline $1 \quad$ (Constant) & 0.240 & 0.091 & & 2.624 & 0.010 \\
\hline
\end{tabular}




\begin{tabular}{llllll} 
IC & 0.001 & 0.002 & 0.072 & 0.801 & 0.425 \\
ISR & 0.319 & 0.107 & 0.271 & 2.987 & 0.003 \\
KP & -0.175 & 0.153 & -0.107 & -1.145 & 0.255 \\
UDPS & 0.014 & 0.024 & 0.053 & 0.580 & 0.563 \\
JRDPS & 0.007 & 0.003 & 0.236 & 2.508 & 0.014 \\
\hline
\end{tabular}

a. Dependent Variable: SP

Sumber : Data SPSS 20 diolah tahun 2020.

\section{PEMBAHASAN}

\section{Pengaruh Intellectual Capital Terhadap Social Performance}

Hasil uji-t menunjukkan nilai koefisien regresi sebesar 0,01 dengan arah positif mempunyai nilai signifikansi $0,425>0,05$. Hal ini menjukkan bahwa variabel independen yaitu variabel intellctual capital tidak berpengaruh terhadap social performance. Hal ini dibuktikan dari hasil yang diperoleh yaitu $\mathrm{t}_{\text {hitung }}<\mathrm{t}_{\text {tabel }}$ nilainya sebesar 0,801 $<1,658$ maka dapat disimpulkan bahwa hipotesis pertama ditolak.

Hasil penelitian ini sejalan dengan penelitian Daud dan Amri (2008) pada perusahaan manufaktur, Solechan (2017) pada perusahaan manufatur, Wibisono dan Panggabean (2019) pada perusahaan manufaktur sektor industri yang menyatakan bahwa intellectual capital tidak berpengaruh terhadap kinerja perusahaan.

\section{Pengaruh Islamic Social Reporting Terhadap Social Performance}

Hasil uji-t menunjukkan nilai koefisien regresi sebesar 0,319 dengan arah positif mempunyai nilai signifikansi $0,03<0,05$. Hal ini menjukkan bahwa variabel independen yang dimasukkan kedalam model regresi yaitu variabel islamic social reporting berpengaruh terhadap social performance. Hal ini dibuktikan dari hasil yang diperoleh yaitu $t_{\text {hitung }} \geq t_{\text {tabel }}$ nilainya sebesar 2,987 > 1,658 maka dapat disimpulkan bahwa hipotesis kedua diterima.

Hasil penelitian ini sejalan dengan penelitian yang dilakukan oleh Saleh, Zulkifli, dan Muhammad (2011) pada perusahaan yang terdaftar di bursa Malaysia, Nugroho dan Rahardjo (2014) perusahaan manufaktur, Evans dan Kartikanindyah (2017) pada perusahaan non-keuangan, Retnaningsih, Hariyanti dan Astuti (2019) pada perbankan syariah bahwa pertanggungjawaban sosial berpengaruh positif terhadap kinerja perusahaan.

\section{Pengaruh Kepemilikan Publik Terhadap Social Performance}

Hasil uji-t menunjukkan nilai koefisien regresi sebesar -0,175 dengan arah negatif mempunyai nilai signifikansi 0,255 >0,05. Hal ini menjukkan bahwa variabel independen yang dimasukkan kedalam model regresi yaitu variabel kepemilikan publik berpengaruh negatif terhadap social performance. Hal ini dibuktikan dari hasil yang diperoleh yaitu $t_{\text {hitung }} \geq t_{\text {tabel }}$ nilainya sebesar 1,145>-1,658 maka dapat disimpulkan bahwa hipotesis ketiga ditolak.

Hasil penelitian ini sejalan dengan penelitian yang dilakukan oleh Raharja (2013) pada perusahaan non-keuangan, Adnantara (2013) pada perusahaan manufaktur dan Arifulsyah (2016) pada perusahaan pertambangan yang menyatakan bahwa struktur kepemilikan publik berpengaruh negatif terhadap kinerja perusahaan. 


\section{Pengaruh Ukuran Dewan Pengawas Syariah terhadap Social Performance}

Hasil uji-t menunjukkan nilai koefisien regresi sebesar 0,014 dengan arah positif mempunyai nilai signifikansi $0,563>0,05$. Hal ini menjukkan bahwa variabel independen yang dimasukkan kedalam model regresi yaitu variabel ukuran dewan pengawas syariah tidak berpengaruh terhadap social performance. Hal ini dibuktikan dari hasil yang diperoleh yaitu $t_{\text {hitung }}<t_{\text {tabel }}$ nilainya sebesar $0,580<1,658$ maka dapat disimpulkan bahwa hipotesis keempat ditolak.

Hasil penelitian ini sejalan dengan penelitian yang dilakukan oleh Mollah dan Zaman (2015), Eksandy (2018), dan Zuliana dan Alamin (2019) menemukan bahwa ukuran dewan pengawas syariah tidak berpengaruh terhadap kinerja perusahaan.

\section{Pengaruh Jumlah Rapat Dewan Pengawas Syariah}

Hasil uji-t menunjukkan nilai koefisien regresi sebesar 0,07 dengan arah positif mempunyai nilai signifikansi $0,014<0,05$ berdasarkan tabel 4.11 . hal ini menjukkan bahwa variabel independen yang dimasukkan kedalam model regresi yaitu variabel jumlah rapat dewan pengawas syariah berpengaruh positif terhadap social performance. Hal ini dibuktikan dari hasil yang diperoleh yaitu $t_{\text {hitung }}<t_{\text {tabel }}$ nilainya sebesar $2,508>1,658$ maka dapat disimpulkan bahwa hipotesis kelima diterima.

Hasil penelitian ini sejalan dengan penelitian yang dilakukan oleh Nurmalia dan Ardana (2019), Amalia dkk.(2019), dan Umam dan Ginanjar (2020) menemukan bahwa jumlah rapat dewan pengawas syariah berpengaruh positif terhadap kinerja perusahaan.

\section{SIMPULAN DAN SARAN}

Simpulan yang dapat diambil dari penelitian ini sebagai berikut : (1) Intellectual Capital tidak berpengaruh terhadap Social Performance, (2) Islamic Social Reporting berpengaruh positif terhadap Social Performance, (3) Kepemilikan Publik berpengaruh negatif terhadap Social Performance, (4) Ukuran Dewan Pengawas Syariah tidak berpengaruh terhadap Social Performance, dan (5) Jumlah Rapat Dewan Pengawas Syariah berpengaruh positif terhadap Social Performance.

Berdasarkan proses penelitian yang telah dilakukan, adapun keterbatasan dalam penelitian ini yaitu hanya memiliki nilai Adjusted $R$ Square sebesar 0,105 atau seebsar $10,5 \%$ yang berarti variabel dependen yaitu social performance hanya dapat dijelaskan oleh variabel intellectual capital, islamic social reporting, kepemilikan publik, ukuran dewan pengawas syariah, dan jumlah rapat dewan pengawas syariah seebsar $10,5 \%$, sisanya dijelaskan oleh variabel lainnya diluar model penelitian sebesar $89,5 \%$.

Berdasarkan kesimpulan dan keterbatasan yang telah dijelaskan diatas, maka peneliti dapat memberikan saran untuk penelitian selanjutnya yaitu diharapkan dapat menambahkan variabel lain seperti reputasi dewan pengawas syariah, rangkap jabatan dewan pengawas syariah, keputusan pendanaan, ukuran dewan direksi dan ukuran komite audit. 


\section{DAFTAR PUSTAKA}

Adnantara, Komang Fridagustina. 2013. Pengaruh Struktur Kepemilikan Saham Dan Corporate Social Responsibility Pada Nilai Perusahaan. Jurnal Buletin Studi Ekonomi. Vol 18(3): 85-190.

Agustina, Heni. dan Soelistya, Djoko. 2018. Analisis Struktur Kepemilikan Perusahaan Terhadap Profitabilitas Perusahaan Makanan Dan Minuman Yang Terdaftar Di BEI. Bussiness And Finance Journal.Vol. 3(2) : 8594.

Almutairi, A. R., \& Quttainah, M. A. 2017. Corporate Governance: Evidence From Islamic Banks. Social Responsibility Journal . Vol. 13 (3): 601624.

Alsartawi, Abdalmuttaleb Musleh. 2019. Performance Of Islamic Banks Do The Frequency Of Sharī'ah Supervisory Board Meetings And Independence Matter?. ISRA International Journal Of Islamic Finance. Vol. 11(2): 303321.

Amalia, Farida., Sasongko, Noer., Bawono, Andi Bayu. 2019. Pengaruh Karakteristik Islamic Corporate Governance, Intellectual Capital Dan Keputusan Pendanaan Terhadap Kinerja Keuangan. The 9th University rsearch Colloqium. Vol. 9(5) : 156:163

Andraeny, D., \& Putri, D. D. (2017). Islamicity Financial Performance Index in Indonesian Islamic Banks. Shirkah Journal of Economics and Business. Vol. 2(3): 2503-4243.

Arifulsyah, Hamdani. 2016. Pengaruh Proporsi Kepemilikan Publik Terhadap Kinerja Keuangan Perusahaan, Dengan Corporate Social Responsibility Disclosure Sebagai Variabel Moderating. Jurnal Akuntansi dan Bisnis. Vol. 9: 58-67.

Barney, Jay B., Ketchen, David J., Jr and Wright, Mike. 2011. The Future of Resource-Based Theory: Revitalization or Decline?. Journal of Management. Vol. 37(5): 1299-1315.

Barney. 1991. Firm Resources and Sustained Competitive Advantage. Journal of Management. Vol. 17(1): 99-120.

Bayoud, N. S., Slaughter, G., \& Kavanagh, M. 2012. An Empirical Study of the Relationship Between Corporate Social Responsibility Disclosure and Organizational Performance: Evidence from Libya. International. Journal of Management and Marketing Research. Vol. 5 (3): 69-82.

Chairunissa, Citra., Dewi, Raden Rosiyana. 2015. Pengaruh Intellectual Capital Terhadap Kinerja Keuangan Perusahaan Dan Penilaian Pasar Dengan Corporate Goverment Sebagai Variabel Moderasi. Jurnal Akutansi Trisakti (E-Journal). Vol. 2(2): 87-102.

Daud, Rulfah M., Amri, Abrar. 2008. Pengaruh Intellectual Capital Dan Corporate Social Responsibility Terhadap Kinerja Perusahaan. Jurnal Telaah dan Riset Akutansi. Vol. 1(2): 213-231.

Dewi, R. K., \& Widagdo, B. 2013. Pengaruh Corporate Social Responsibility Dan Good Corporate Governance Terhadap Kinerja Perusahaan. Manajemen Bisnis. Vol. 2(1). 
Eforis, Chermian. 2017. Pengaruh Kepemilikan Negara Dan Kepemilikan Publik Terhadap Kinerja Keuangan BUMN. Ultima Accounting : Jurnal Ilmu Akuntansi. Vol. 9(1): 18-31.

Eksandy, A., 2018. Pengaruh Good Corporate Governance Terhadap Kinerja Keuangan Pada Perbankan Syari'ah Indonesia. JAK (Jurnal Akuntansi): Kajian Ilmiah Akuntansi. Vol. 5(1):1-10.

Evans, jeanet Christanty., dan Kartikaningdyah, Ely. Pengaruh Corporate Social Responsibilty Terhadap Kinerja Keuangan Perusahaan. Journal of Applied Managerial Accounting. Vol. 1(1): 37-44.

Freeman, R.E.. 1984. Starategic Management: A Stakeholders Approach. Cambridge University Press.

Ghozali, I dan Chariri, A, 2007. Teori Akuntansi. Semarang: Badan Penerbit UNDIP

Ghozali, Imam. 2013. Aplikasi Analisis Multivariate Dengan Program SPSS. Semarang : Badan Penerbit Universitas Diponegoro.

Hamdani, Shifa Putri., Yuliandari, Willy Sri., dan Budiono, Eddy. 2017. Kepemilikan Saham Publik Dan Return On Assets Terhadap Pengungkapan Corporate Social Responsibility. Jurnal Riset Akuntansi Kontemporer. Vol. 9(1): 47-54.

Hameed, S., Wirman, A., Alrazi, B., Nazli, M., \& Pramono, S. 2004. Alternative Disclosure and Performance Measures for Islamic Banks. In Second Conference on Administrative Sciences: Meeting the Challenges of the Globalization Age, King Fahd University of Petroleum \& Minerals, Dhahran, Saudi Arabia. pp. 19-21.

Haniffa, Roszaini. 2002. Social Reporting Disclosure: An Islamic Perspective. Indonesian Management and Accounting Research. Vol. 1(2): 128-146

Haryanti dan Rahardjo. 2013. Pengaruh Corporate Social Responsibility, Kinerja Lingkungan, Dan Struktur Corporate Governance Terhadap Kinerja Keuangan Perusahaan Yang Terdaftar Di Bursa Efek Indonesia. Dipenogoro Journal of Accounting. Vol. 2(2) : 1-15.

Indrayani. 2018. Pengaruh Islamic Corporate Social Responsibility (ICSR) Dan Sharia Governance Terhadap Kinerja Perusahaan. Jurnal Akuntansi, Keuangan \& Perpajakan Indonesia. Vol. 6(1): 68-80.

Innayah, Maulida Nurul., Pratama, Bima Cinintya., dan Hanafi, Maduh Mahmadah. 2020. The Effect of Intellectual Capital towards Firm Performance and Risk with Board Diversity as a Moderating Variable: Study in ASEAN Banking Firms. Jurnal Dinamika Manajemen. Vol. 11(1): 26-37.

Irwansyah, Rakhmat. 2019. Pengaruh Komisaris Independen, Komite Audit Independen, Pergantian Chief Executive Officer Dan Struktur Kepemilikan Saham Publik Terhadap Return On Asset (Studi Empiris Pada Perusahaan Properti Dan Real Estate Di Bursa Efek Indonesia). Transparasi Jurnal Ilmiah Administrasi. Vol. 2(1): 20-36.

Jensen, M.C., and Meckling, W.H. 1976. Theory of the Firm: Managerial Behavior, Agency Costs and Ownership Structure. Journal of Financial Economics. Vol. 3(4): 305-360. 
Kozlenkova, I. V., S. A. Samaha, and R. W. Palmatier. 2014. Resource-based theory in marketing. Journal of the Academy of Marketing Science. Vol. 42 (1): $1-21$.

Makruflis, M., 2019. Pengukuran Kesehatan Bank Syariah Berdasarkan Islamicity Performance Index. IQTISHADUNA: Jurnal Ilmiah Ekonomi Kita. Vol. 8(2): 225-236.

Merina, Citra Indah., dan Verawaty. 2016. Analisis Komparasi Indeks Islamic Social Reporting Perusahaan Perbankan Syariah Dan Perusahaan Go Publik Yang Listing Di Jakarta Islamic Index. Jurnal AKUISISI. Vol. 12(2): 1-17.

Mollah, S., and Zaman, M. 2015. Shari'ah Supervision, Corporate Governance And Performance: Conventional VS Islamic Banks. Journal of Banking and Finance. Vol. 58: 418-435.

Muttakin, M.B., and M.S.Ullah. 2012. Corporate Governance and Bank Performance: Evidence from Bangladesh. Corporate Board: Role, Duties \& Composition. Vol. 8 (1): 62-68.

Nomran, Naji Mansour., Haron, Razali., Hassan, Rusni. 2018. Shari'ah Supervisory Board Characteristics Effects On Islamic Banks' Performance Evidence From Malaysia. International Journal of Banks. Vol. 36(2):290-304.

Nugroho. Faizal Adi., Rahardjo, Shiddiq Nur. 2014. Analisis Pengaruh Corporate Social Responsibility Dan Karakteristik Good Corporate Governance Terhadap Kinerja Perusahaan. Dipenogoro Journal of Accounting. Vol. 3(2): 1-10.

Nurgraheni, Peni. 2018. Sharia Supervisory Board And Social Performance Of Indonesia Islamic Banks. Jurnal Akutansi Dan Auditing Indonesia. Vol 22(2): 137-147.

Nurhayati, Euis., Yuliafitri, Indri., Amrania, Gia Kardina Prima. 2017. Analisis Pengaruh Islamic Social Reporting, Ukuran, Dan Jumlah Rapat DPS Terhadap Manajemen Laba Perbankan Syariah Di Indonesia. Jurnal Banque Syar'i. Vol. 3(1): 43-78.

Nurmalia, G., \& Ardana, Y. (2019). Analisis Pelaporan Zakat, ICSR, Dewan Pengawas Syariah dan Leverage dalam Mengungkapkan Kinerja Bank Umum Syariah di Indonesia. Cakrawala: Jurnal Studi Islam. Vol. 14(2):113-122.

Nurvita, Tita. 2018. Corporate Governance Pada Perbankan Syariah Dan Hubungannya Dengan Kinerja Keuangan. Jurnal Ilmiah Bisnis, Pasar Modal, dan UMKM. Vol. 1(2): 19-29.

Otoritas Jasa Keuangan. 2009. Peraturan Bank Indonesia Nomor 11/3/PBI/2009 Tentang Bank Umum Syariah. https://www.ojk.go.id/id/kanal/perbankan/regulasi/peraturan-bankindonesia/Pages/peraturan-bank-indonesia-nomor-11-3-pbi-2009.aspx. [Diakses 10 Oktober 2020]

Otoritas Jasa Keuangan. 2020. Penyampaian Laporan Tahunan Emiten atau Perusahaan Publik Berdasarkan keputusan Ketua Badan Pengawas Pasar Modal dan Lembaga Keuangan Nomor KEP-431/BL/2012.. https://www.ojk.go.id/id/regulasi/Pages/BAPEPAM-XK6-tentang- 
RATIO: Reviu Akuntansi Kontemporer Indonesia 2021, 2 (2)

Penyampaian-Laporan-Tahunan-Emiten-atau-Perusahaan-Publik.aspx.

[Diakses 27 Januari 2021]

Otoritas Jasa Keuangan. 2020. Statistik Perbankan Syariah-Juli 2020.

https://www.ojk.go.id/id/kanal/syariah/data-dan-statistik/statistik-

perbankan-syariah/Documents/Pages/Statistik-Perbankan-Syariah---Juli-

2020/SPS\%20Juli\%202020.pdfperbankan-

syariah/Documents/Pages/Statistik-Perbankan-Syariah---Juli-

2020/SPS\%20Juli\%202020.pdf. [Diakses 10 Oktober 2020]

Prasetyo, Agung., Meiranto, Wahyu. 2017. Pengaruh Corporate Social

Responsibility Terhadap Kinerja Keuangan Perusahaan Manufaktur

Yang Terdaftar Di BEI Tahun 2013 - 2015. Diponegoro Journal Of

Accounting. Vol. 6(3): 260-371.

Pratama, B.C., Wibowo, H., \& Innayah, M.N. 2019. Intellectual Capital and Firm Performance in ASEAN: The Role of Research and Development.

Journal of Accounting and Investment. Vol. 20(3): 236-250.

Pratama, Bima Cinintya. 2016.The Impact Of Intellectual Capital Of Indonesian's Hight-Tech Company on Firm's Fiancial and Market Performance. International Journal Of Academic Research In Accounting, Finance And Management Sciences. Vol 6(4): 73-81.

Pratama, Bima Cinintya. 2018. Family Ownership Role in Strengthening the Relationship Between Intellectual Capital and Financial Performance: Research in High-Tech Firms in Indonesia and Philippines. Advances in Social Science, education and Humanities Research. Vol. 231: 326-329.

Purwanti, Ari. 2016. Dewan Pengawas Syariah Dan Pengungkapan Aspek Lingkungan, Produk Dan Jasa Pada Bank Syariah. Jurnal Akuntansi dan Keuangan Islam. Vol. 4(2): 171-182.

Rahmawati, Inge Andhitya., Rikumahu, Brady., Dillak, Vaya Juliana. 2017. Pengaruh Dewan Direksi, Dewan Komisaris, Komite Audit Dan Corporate Social Responsibility Terhadap Kinerja Keuangan Perusahaan. Jurnal Akutansi \& Ekonomi FE UN PGRI Kediri.Vol. 2(2): 54-70.

Rahmawati, N.B., dan Handayani, S. 2017. Analisis Pengaruh Karakteristik Corporate Governance Terhadap Kinerja Perusahaan (Studi Empiris pada Perusahaan Manufaktur yang Terdaftar di Bursa Efek Indonesia periode 2010-2014). Diponegoro Journal Of Accounting. Vol. 6(3): 1-12.

Retnaningsih, Susi. Hariyanti, Widi. Astuti, titiek puji. 2019. Pengaruh Pengungkapan Islamic Social Reporting (ISR) terhadap Kinerja Keuangan pada Perbankan Syariah di Indonesia tahun 2012-2016. AKTSAR : Jurnal Akutansi Syariah. Vol. 2( 2): 169-186.

Reza, M. and Violita, E.S., 2018. Pengaruh Penerapan Nilai-Nilai Islam Terhadap Kinerja Bank Syariah dengan Menggunakan Maqashid Index: Studi Lintas Negara. Jurnal Dinamika Akuntansi dan Bisnis. Vol.5(1): 17-30.

Saleh, Mustaruddin., Zulkifli, Norhayah., Muhamad, Rusnah. 2011. Looking For Evidence Of The Relationship Between Corporate Social Responsibility And Corporate Financial Performance In An Emerging Market. Asia Pacific Journal Of Business Administration. Vol. 3(2): 155-190 
Samad, Abdus \& Hassan, Kabir. 1999. The Performance of Malaysian Islamic Bank during 1984-1997: an Exploratory Study. International Journal of Islamic Financial Service. Vol. 1(3).

Solechan. 2017. Pengaruh Efisiensi Modal Intelektual Terhadap Kinerja Keuangan perusahaan di Indonesia. Jurnal Kajian Akuntansi. Vol. 1: 8396.

Ullman, A. A. 1985. Data in Search of a Theory: A Critical Examination of the Relationships among Social Performance, Social Disclosure, and Economic Performance of U.S. Firms. Academy of Management Review. Vol. 10(3): 540-57.

Ulum, Ihyaul. 2013. Model Pengukuran Kinerja Intellectual Capital Dengan iBVAIC Di Perbankan Syariah. Jurnal Penelitian Sosial Keagamaan.Vol. 7(1): 185-206.

Umam, Mochamad Febri Sayidil., Ginanjar, Yogi. 2020. Pengaruh Dewan Pengawas Syariah Dan Proporsi Dewan Komisaris Independen Terhadap Kinerja Keuangan Perbankan Syariah Indonesia. Jurnal Ekonomi Syariah dan Bisnis. 3(1): 72-80.

Wardani, R.P. 2012. Faktor-Faktor Yang Mempengaruhi Luas Pengungkapan Sukarela. Jurnal Akuntansi Dan Keuangan. Vol. 14(1): 1-15.

Wibisono, Edwin. Panggabean, Rosinta Ria. 2019. Pengaruh Corporate Social Responsibility Dan Intellectual Capital Terhadap Kinerja Keuangan. Balance : Jurnal Akutansi, Auditing Dan Keuangan. Vol. 16(1): 62-92.

Wibisono, Y. 2007. Membedah Konsep dan Aplikasi Corporate Social Responsibility. Cetakan Kedua. Gresik: Fancho Publishinggh

Zuliana, Renny., Dan Aliamin. 2019. Pengaruh Dewan Pengawas Syariah, Intellectual Capital Dan Corporate Social Responsibility Terhadap Kinerja Bank Syariah Di Indonesia. Jurnal Ilmiah Mahasiswa Ekonomi Akutansi. Vol 4(4): 677-694. 